Document downloaded from:

http://hdl.handle.net/10251/28637

This paper must be cited as:

Sencadas, VJGDS.; Pitaes, A.; Benelmekki, M.; Gómez Ribelles, JL.; Lanceros Mendez, S. (2011). Influence of ferrite nanoparticle type and content on the crystallization kinetics and electroactive phase nucleation of poly(vinilidene fluoride). Langmuir. 27(11):7241-7249. doi:10.1021/la2008864

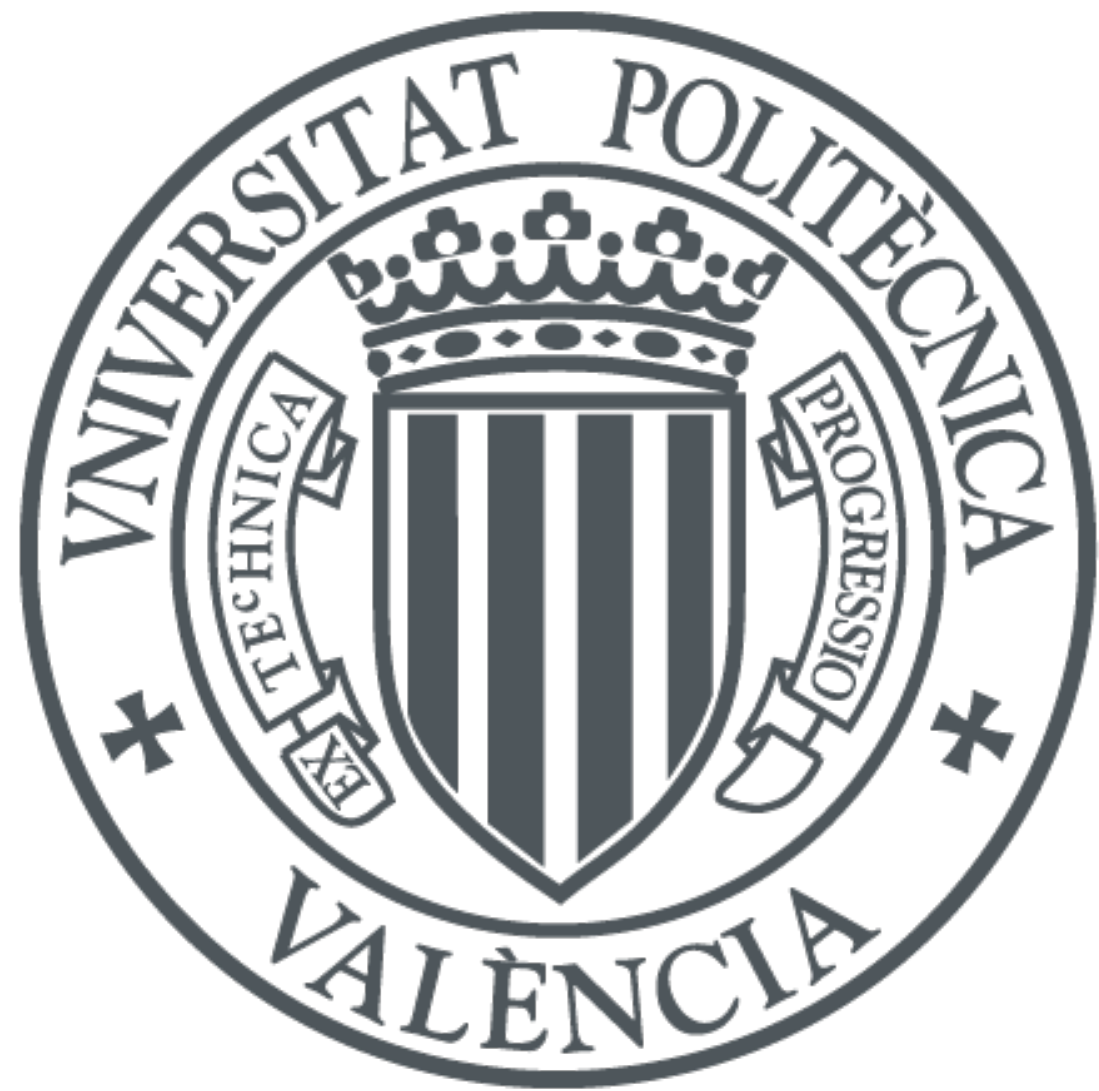

The final publication is available at

http://pubs.acs.org/doi/abs/10.1021/la2008864

Copyright American Chemical Society

Additional Information

"This document is the Accepted Manuscript version of a Published Work that appeared in final form in

[JournalTitle], copyright (C) American Chemical Society after peer review and technical editing by the publisher.

To access the final edited and published work see [insert ACS Articles on Request authordirected link to http://pubs.acs.org/doi/abs/10.1021/la2008864 


\title{
Influence of ferrite nanoparticle type and content on the crystallization kinetics and electroactive phase nucleation of poly(vinilidene fluoride)
}

Vitor Sencadas ${ }^{1}$ Pedro Martins ${ }^{1}$, Alexandre Pitães ${ }^{1,2}$, Maria Benelmekki ${ }^{1}$, José Luis Gómez-Ribelles ${ }^{2,3,4}$ and Senentxu Lanceros-Mendez ${ }^{1^{*}}$

*lanceros@fisica.uminho.pt

${ }^{1}$ Centro/Departamento de Física, Universidade do Minho, Campus de Gualtar, 4710058 Braga, Portugal

2 Center for Biomaterials and Tissue Engineering,, Universidad Politécnica de Valencia, Camino de Vera s/n, 46022 Valencia, Spain

${ }^{3}$ Prince Felipe Research Center, Autopista del Saler 16, 46013 Valencia, Spain

${ }^{4}$ Networking Research Center on Bioengineering, Biomaterials and Nanomedicine (CIBER-BBN), Valencia, Spain

\begin{abstract}
This work reports on the nucleation of the $\beta$-phase of poly(vinylidene fluoride), PVDF, by incorporating $\mathrm{CoFe}_{2} \mathrm{O}_{4}$ and $\mathrm{NiFe}_{2} \mathrm{O}_{4}$ nanoparticles, leading in this way, to the preparation of magnetoelectric composites. The fraction of filler nanoparticles needed to produce the same $\beta$ - to $\alpha$-phase ratio in crystallized PVDF is one order of magnitude lower in the Cobalt nanoparticles. The interaction between nanoparticles and PVDF chains induce the all trans conformation in PVDF segments and this structure then propagates in crystal growth. The nucleation kinetics is enhanced by the presence of nanoparticles, as corroborated by the increasing number of spherulites with increasing nanoparticle content and by the variations of the Avrami's exponent. Further, the decrease of the crystalline fraction of PVDF with increasing nanoparticles content indicates that an important fraction of polymer chains are confined in interphases with the filler particle.
\end{abstract}


Keywords: Kinetics, PVDF, Electroactive Polymers, Isothermal Crystallization, Magnetoelectric composites

PACS: 64.70.dg; 64.70.km; 68.55.am

\section{Introduction}

Polymer nanocomposites represent a class of materials with improved performance. Compared with traditional filled grades of polymers, nanocomposites show property improvements at lower loadings of the inorganic fillers ${ }^{1}$.

Among the electroactive polymers, Poly(vinylidene Fluoride) (PVDF) and its copolymers, represent the family of polymers with the best electroactive performance 2,3. PVDF shows typically a degree of crystallinity around $50 \%$ and can appear in four different crystalline phases known has $\alpha, \beta, \gamma$ and $\delta$, depending on the processing conditions ${ }^{4}$. The $\alpha$ and $\beta$-phases are the most important crystalline polimorphs. The $\alpha$ phase is non-polar and has a trans-gauche bond (TGTG') conformation, being most commonly obtained directly cooling from the melt or by solvent cast at solvent evaporation temperatures above $120{ }^{\circ} \mathrm{C}^{5-7}$. The $\beta$-phase, with an "all-trans" conformation (TTT) comprising fluorine and hydrogen atoms on opposite sides of the polymer chain, resulting in a net non-zero dipole moment, which results in the most polar phase, being extensively applied in technological applications involving the electroactive properties of the material ${ }^{3,8}$.

Typically, the $\beta$-PVDF is obtained by stretching the $\alpha$-phase t temperatures below 100 ${ }^{\circ} \mathrm{C}$ with a draw ratio between 3 and $5^{3,6}$. Unoriented $\beta$-phase may also be obtained by solvent casting, when the material is crystallized at temperatures below $70{ }^{\circ} \mathrm{C}$, but the samples obtained by this procedure presents high porosity ${ }^{6}$. Solvent evaporation at higher temperatures results in a mixture of the $\alpha$ and $\beta$-phase, with the $\alpha$-phase fraction increasing with increasing temperature ${ }^{3,6}$. A method to remove the porosity of such samples was developed by Sencadas et al. by applying a uniaxial compression force at temperatures above $140{ }^{\circ} \mathrm{C}^{6}$. Due to the high porosity of the samples, the material has very poor mechanical and electrical properties, what reduce the applicability of these materials as sensors and actuators. 
Consequently, some other methods were introduced to improve the way in which the $\beta$ PVDF phase is obtained. Among them, crystallization under high pressure or the use of copolymers such as poly(vinylidene trifluorethylene) ( $\mathrm{P}(\mathrm{VDF}-\mathrm{TrFE})$ ) resulting from the copolymerization of vinylidene fluoride (VDF) with trifluoroethylene are examples of such efforts $^{9}$. Other method to develop a $\beta$-PVDF is based on the incorporation of nanoclay into $\mathrm{PVDF}^{1,10}$.

Most recently, ferrite nanoparticles were added to PVDF with the intention of nucleate the electroactive phase of the polymer ${ }^{11,12}$. These ferrite nanoparticles are usually used as the ferromagnetic phase in magnetoelectric composites and are interesting both for fundamental studies and technological applications ${ }^{13}$. Nanometer size ferrites are under intense investigation due to the broad range of magnetic behavior that is used for the preparation of tailored composites and structures ${ }^{14}$.

The physical properties of PVDF depend upon the processing conditions and can also be strongly influenced by the presence of nanoparticles, which affect the crystallization behavior and the resulting polymer morphology ${ }^{15}$. Additionally, the presence of nanoparticles also has influence on crystallization kinetics ${ }^{16}$.

Despite crystallization behaviour of the $\alpha$-phase PVDF has been already studied ${ }^{17}$ the effect of nanoparticles in the polymer crystallization remains vaguely discussed ${ }^{16,18}$.

Recent publications reveal that addition of nanoparticles into PVDF matrix shift the crystallization peak to higher temperatures and smaller spherulites are created ${ }^{12,16}$. This suggests that the faster crystallization rate of PVDF observed in the blends is due to the nucleating ability of nanoparticles.

In a general way, the subject of polymer crystallization has been of great interest for several decades and can be carried out under isothermal or non-isothermal conditions ${ }^{19}$. Studies on the overall crystallization rate under isothermal conditions are usually accomplished in the scope of the Avrami formalism ${ }^{20-22}$ which is valid at least for the early stages of the process ${ }^{17,23}$.

Non-isothermal crystallization of polymers, on the other hand, is not easy to be modeled. This difficulty has been overcome by assuming the non-isothermal process as an approximation of infinitesimally small isothermal stages, so that it can be described by models based on modifications of the initial Avrami equation ${ }^{17,23,24}$.

The non-isothermal crystallization kinetics of several polymeric nanocomposites has been discussed. $\mathrm{Xu}$ et $\mathrm{al}^{25}$ reported that the crystallization of Polypropylene/Montmorillonite nanocomposites was faster than the pure Polypropylene 
at a given cooling rate. The addition of Montmorillonite accelerates then the overall nonisothermal crystallization and reduces the activation energy. Qian et al. ${ }^{26}$ showed that the crystallization rate of high-density polyethylene (HDPE)/nano- $\mathrm{SiO}_{2}$ nanocomposite was faster than that of pure HDPE and that the activation energies of the composites increased with the increasing $\mathrm{SiO}_{2}$ loading.

The nucleation activities of silica nanoparticles were also investigated by Kim et al. ${ }^{27}$. The addition of nano-sized silica nanoparticles shift the crystallization peaks to higher temperatures compared with the pure poly(ethylene 2,6-naphthalate) (PEN), and the overall crystallization time was reduced. On the other hand, the degree of crystallinity of PEN nanocomposites was increased.

More recently, Kim et al. and Manna et al. took advantage of carbon nanotubes and silver nanoparticles respectively to act as nuclei in the crystallization process of the piezoelectric $\beta$-phase of the polymer $\mathrm{PVDF}^{28,29}$. It was found that melting temperature and enthalpy of fusion of PVDF increased slightly in the PVDF/silver nanoparticles; however, with increasing Ag nanoparticle content they gradually decreased. The crystallization studies on cooling from the melt indicated that silver nanoparticles acted as nucleating agents for crystallization of PVDF.

Regarding isothermal crystallization kinetics of polymer nanocomposites, Chen et $\mathrm{al}^{30}$, using the Avrami analysis, demonstrated that adding organo-attapulgite (ATT) into Poly(butylene terephthalate) accelerate the crystallization kinetics of PBT. Similar results were found by Zhang et al. ${ }^{31}$ when added Carbon black (CB) nanoparticles into poly(ethylene terephthalate) (PET). The crystallization temperature decreased from 393 to $373 \mathrm{~K}$ with increasing $\mathrm{CB}$ content from 0 to $12.5 \mathrm{wt} \%$. Avrami exponents $n$ were evaluated to be in the range 2.1-2.6 for neat PET and the composites. Carbon black nanoparticles acting as nucleating agent in the composites accelerated the crystallization rate, and the crystallinity of the composites was improved largely by addition of CB.

Concerning the isothermal crystallization, Raka et al. ${ }^{32}$ reported the effect of organomodified clay (Cloisite 93A) nanoparticles on the isothermal crystallization behavior of isotactic polypropylene (iPP) in iPP/clay nanocomposites. Results indicated that higher nanoparticle clay loading promotes the formation of the $\beta$-phase crystallites. Analysis of the isothermal

crystallization showed that the PP nanocomposite (1\% C93A) exhibited higher crystallization rates than the neat PP and that the activation energy decreased with the 
incorporation of clay nanoparticles into the matrix, which in turn indicates that the nucleation process is facilitated by the presence of clay.

In present work, ferrite nanoparticles were added into PVDF via solution blending with different concentrations to obtain PVDF/ferrite magnetoelectric composites. The used ferrites $\left(\mathrm{CoFe}_{2} \mathrm{O}_{4}\right.$ and $\left.\mathrm{NiFe}_{2} \mathrm{O}_{4}\right)$ have the ability to nucleate the ferroelectric phase of the polymer, but they do it at a tailored concentration rate. Further, the crystallization dynamic has been studied in order to shed some light on the influence of the nanoparticles in the crystallization in the different phases of the polymer. Finally, this study is relevant as allows the preparation of magnetoelectric composites taking advantage of the piezoelectric properties of the $\beta$-phase of PVDF and the magnetostriction of the ferrite nanoparticles.

\section{Experimental}

\section{Sample preparation and characterization}

Ferrite nanoparticles were purchased from Nanoamor. $\mathrm{CoFe}_{2} \mathrm{O}_{4}$ and $\mathrm{NiFe}_{2} \mathrm{O}_{4}$ powders have dimensions between 35-55 and 20-30 nm, respectively. The size distribution of the nanoparticles was further determined by Dynamic Light Scattering (Figure 1). N,Ndimethylformamide (DMF, pure grade) was obtained from Fluka and Poly(vinilidene fluoride) (PVDF, Solef 1010) was supplied by Solvay. All the chemicals and nanoparticles were used as received from the suppliers. The initial concentration of the solution was $0.2 \mathrm{~g}$ of PVDF for $1 \mathrm{ml}$ of DMF. In order to obtain a good dispersion of the ferrite nanoparticles within the polymeric matrix, the following procedure was applied: first, the desired amount of nanoparticles was added to $12 \mathrm{ml}$ of DMF and then placed in ultrasound bath during $6 \mathrm{~h}$, to ensure that nanoparticles were well dispersed in the solution and to avoid loose aggregates; then $3 \mathrm{~g}$ of PVDF were subsequently added. Finally, the mixture was placed in a Teflon mechanical stirrer for complete dissolution of the polymer. Flexible films were obtained by spreading the solution on a clean glass substrate.

Solvent evaporation and polymer crystallization were obtained inside an oven at controlled temperature. The samples were maintained inside the oven for $10 \mathrm{~min}$ at 210 ${ }^{\circ} \mathrm{C}$ to ensure the complete melting of the nanocomposite and solvent evaporation. After 
this process, samples are crystallized by cooling down to room temperature. The weight fraction of ferrite nanoparticles varied from 0.1 to $5 \%$ in the case of cobalt ferrite and from 5 to $50 \%$ in the case of nickel ferrite.

Infrared measurements were performed in order to determine and characterize the presence of the different PVDF crystalline phases. A Perkin-Elmer Spectrum 100 apparatus was used in ATR mode from 4000 to $650 \mathrm{~cm}^{-1}$. FTIR spectra were collected with 32 scans and a resolution of $4 \mathrm{~cm}^{-1}$.

Dynamic light scattering (DLS) was performed with a Zetasizer Nano ZS (Malvern instruments), provided by a He/Ne laser of $633 \mathrm{~nm}$ wavelength. The NPs dispersion was analyzed in a polystyrene cell for size distribution.

\section{Crystallization Kinetics}

Crystallization kinetics of PVDF was measured by means of isothermal experiments and cooling scans using a differential scanning calorimeter (DSC) Pyris (Perkin-Elmer, Waltham, MA, USA). Dry nitrogen gas was let through the DSC cell with a flow rate of $20 \mathrm{~mL} \cdot \mathrm{min}^{-1}$. A single sample of each material, around $2 \mathrm{mg}$ weight, directly cut from the film was used for all isothermal experiments. All the samples had approximatelly the same weight (2 mg) and the same thickness, around $50 \mu \mathrm{m}$. The calibration of the DSC was made using the 4-cyano-40-octyloxybiphenyl (M24) transition from smectic to nematic phase, $\mathrm{T}_{\mathrm{s}-\mathrm{n}}$, measured at different temperature rates on cooling and heating runs and the melting point of indium measured at different heating rates. The measurements were conducted with the standard calibration of the DSC and the temperature scale was then corrected by software taking into account the rate dependence of $\mathrm{T}_{\mathrm{s}-\mathrm{n}}$ and the indium melting.

Images of spherulitic growth during the crystallization of PVDF were obtained by optical microscopy with polarized light (OMPL) (Leica DM2500M, Portugal) provided with a Leica DFC-280 camera (Portugal). 


\section{Results}

\section{a) Polymer phase content within the composite}

As already reported in other works, the inclusion of nanofillers like carbon nanotubes or silver nanoparticles changes the crystallization behavior of the polymeric matrix ${ }^{33,34}$. In this work, PVDF nanocomposites were prepared with two different ferrites $\left(\mathrm{CoFe}_{2} \mathrm{O}_{4}\right.$ and $\mathrm{NiFe}_{2} \mathrm{O}_{4}$ ) and different concentration of the filler in the polymeric matrix in order to understand the effect of the filler in the crystallization behavior of the nanocomposite and the ability of the ferrites in induce crystallization of the $\beta$-PVDF directly from the melt.

The infrared measurements for the samples with different filler types and contents are presented in Figure 1. It is observed that, when cooled from the melt, the pure polymer crystallizes directly in the $\alpha$-PVDF crystalline phase. For the nanocomposite samples the FTIR measurements shows that $\alpha$ and $\beta$ crystalline phases coexist in the polymer matrix, with increasing amount of $\beta$-PVDF with increasing ferrite filler content.
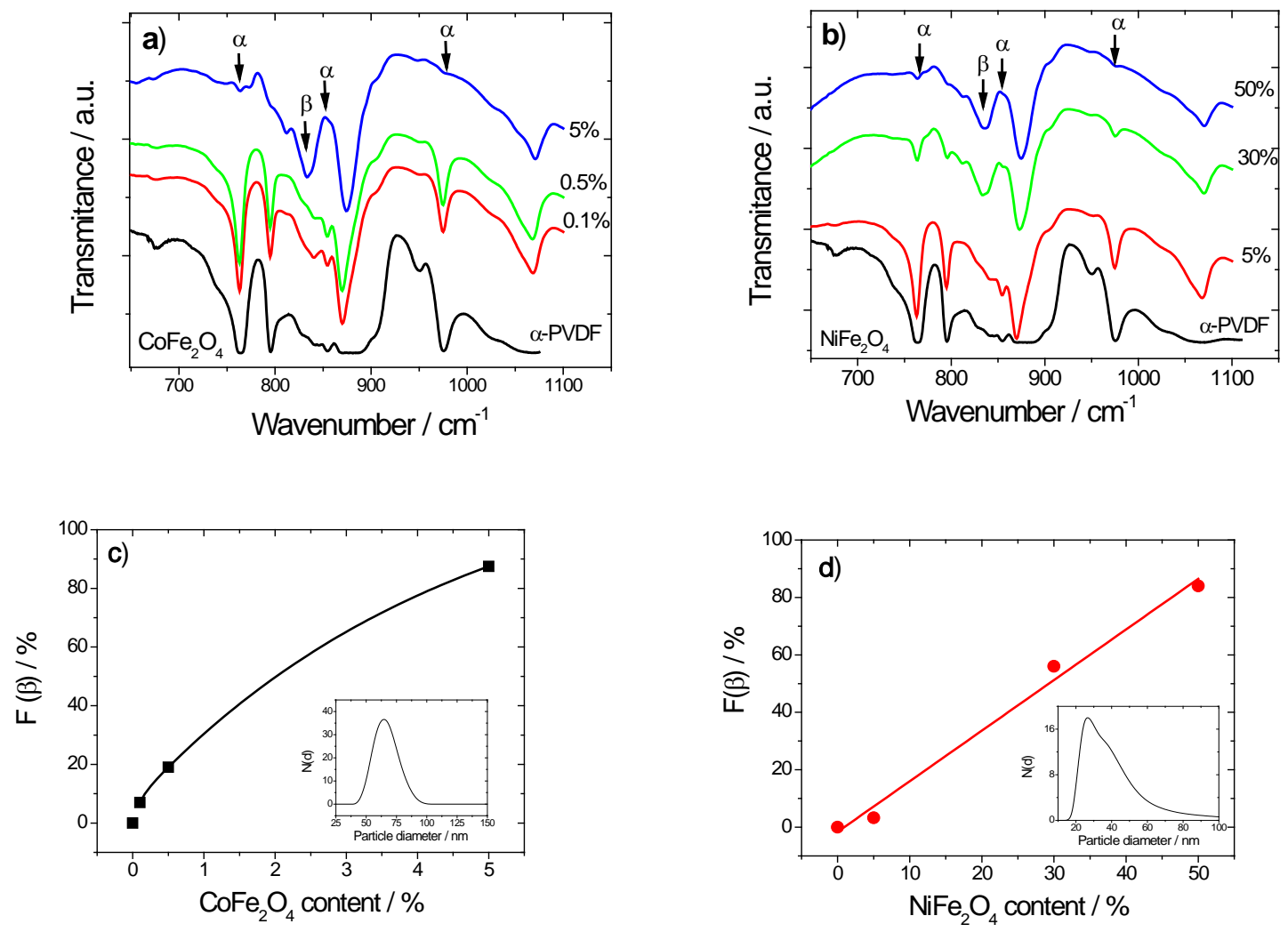
Figure 1 - Infrared spectra for the PVDF nanocomposites with increasing filler contents: a) CoFe2O4, b) NiFe2O4. Evolution of the $\beta$-phase content with increasing filler concentration for the $c$ ) $\mathrm{CoFe}_{2} \mathrm{O}_{4}, d$ ) $\mathrm{NiFe}_{2} \mathrm{O}_{4}$ nanocomposite samples. Inset of figures c) and d): size distribution of the $\mathrm{CoFe}_{2} \mathrm{O}_{4}$ and $\mathrm{NiFe}_{2} \mathrm{O}_{4}$ nanoparticles as obtained by DLS.

The $\beta$-phase content present in each sample was calculated from the infrared absorption bands at $764 \mathrm{~cm}^{-1}$ and $840 \mathrm{~cm}^{-1}$, characteristic of the $\alpha$ and $\beta$-phases of PVDF, respectively, with a procedure similar to the one presented $\mathrm{in}^{3}$. Assuming that the infrared absorption follows the Lambert-Beer law, for a system containing $\alpha$ and $\beta$ phases, the relative fraction of the $\beta$-phase, $F(\beta)$, can be calculated applying equation (1):

$$
F(\beta)=\frac{X_{\beta}}{X_{\alpha}+X_{\beta}}=\frac{A_{\beta}}{\left(K_{\beta} / K_{\alpha}\right) A_{\alpha}+A_{\beta}}
$$

where $A_{\beta}$ and $A_{\alpha}$ are the absorbance at 840 and $764 \mathrm{~cm}^{-1}$, respectively and $K_{\beta}$ and $K_{\alpha}$ are the absorption coefficients at the respective wavenumber. For the nanocomposite samples, the variation of the relative fraction of the $\beta$-phase with increasing amount of $\mathrm{CoFe}_{2} \mathrm{O}_{4}$ and $\mathrm{NiFe}_{2} \mathrm{O}_{4}$ ferrite fillers is presented in Figure 1 ( $c$ and $d$ ). For $\mathrm{CoFe}_{2} \mathrm{O}_{4}$, even a small amount of nanoparticles induces the crystallization of the polymer matrix and the co-existence of the $\alpha$ and $\beta$-phases of PVDF. Figure 1c shows that a maximum of $88 \%$ of $\beta$-phase is obtained for $5 \%$ of $\mathrm{CoFe}_{2} \mathrm{O}_{4}$ content. On the other hand, for the $\mathrm{NiFe}_{2} \mathrm{O}_{4}$ co-existence of $\alpha$ and $\beta$-phases is observed for small filler content, too, but to obtain the highest amount of $\beta$-phase $84 \%$, it is necessary to add as much as $50 \% \mathrm{wt}$ $\mathrm{NiFe}_{2} \mathrm{O}_{4}$ nanoparticles. It is to notice that the density of $\mathrm{CoFe}_{2} \mathrm{O}_{4}\left(5.3 \mathrm{~g} / \mathrm{cm}^{3}\right)$ and $\mathrm{NiFe}_{2} \mathrm{O}_{4}\left(5.4 \mathrm{~g} / \mathrm{cm}^{3}\right)$ is quite similar, representing therefore similar volume content for the same mass content.

\section{b) Composite microstructural morphology}


The morphology of the samples during polymer crystallization was observed by polarized optical microscopy (POM) a technique that evidences that the crystalline morphology of PVDF is highly influenced by the presence of ferrite nanoparticles. Figure 2 shows the spherulitic structure of the semi-crystalline $\alpha$-PVDF (Figure 2a), PVDF filled with Cobalt and Nickel Ferrite nanocomposites, respectively (Figures $2 b$ and 2c). The spherulites of PVDF present a compact and well-defined structure with Maltese-cross texture (Figure 2), as it was shown in a previous paper ${ }^{17}$. The addition of even the smallest amount of Cobalt ferrite nanoparticles, $0.1 \% w t$, increases the number of the spherulites while spherulite size decreases strongly (Figure 2b), but the samples reveal almost the same spherulitic microstructure as for the $\alpha$-phase of the PVDF. This is a clear evidence that nanoparticles act as nucleation points. Nevertheless it is worth note that the increase in the number of spherulites is orders of magnitude smaller than the number of nanoparticles. Only some of them initiate growing of a spherulite while the rest are embedded in the growing crystalline structure. With increasing $\mathrm{CoFe}_{2} \mathrm{O}_{4}$ nanoparticle content, the number of nucleation points grows so much that spherulites cannot be formed. In fact, the sample containing $5 \%$ wt $\mathrm{CoFe}_{2} \mathrm{O}_{4}$ (Figure 2c) show no texture in the polarized light microscope in spite that, as will be shown by the DSC results, below, its crystalline fraction is nearly the same than in pure PVDF. In the case of $\mathrm{NiFe}_{2} \mathrm{O}_{4}$ nanocomposites it was impossible to observe the crystalline structure except in the sample with the smallest nanoparticles content since the higher particles concentration of the other two turned the samples almost opaque (Figure 2d). Nanocomposites with $5 \%$ wt $\mathrm{NiFe}_{2} \mathrm{O}_{4}$ show a large number of very small spherulites proving that these particles are also able to nucleate PVDF.
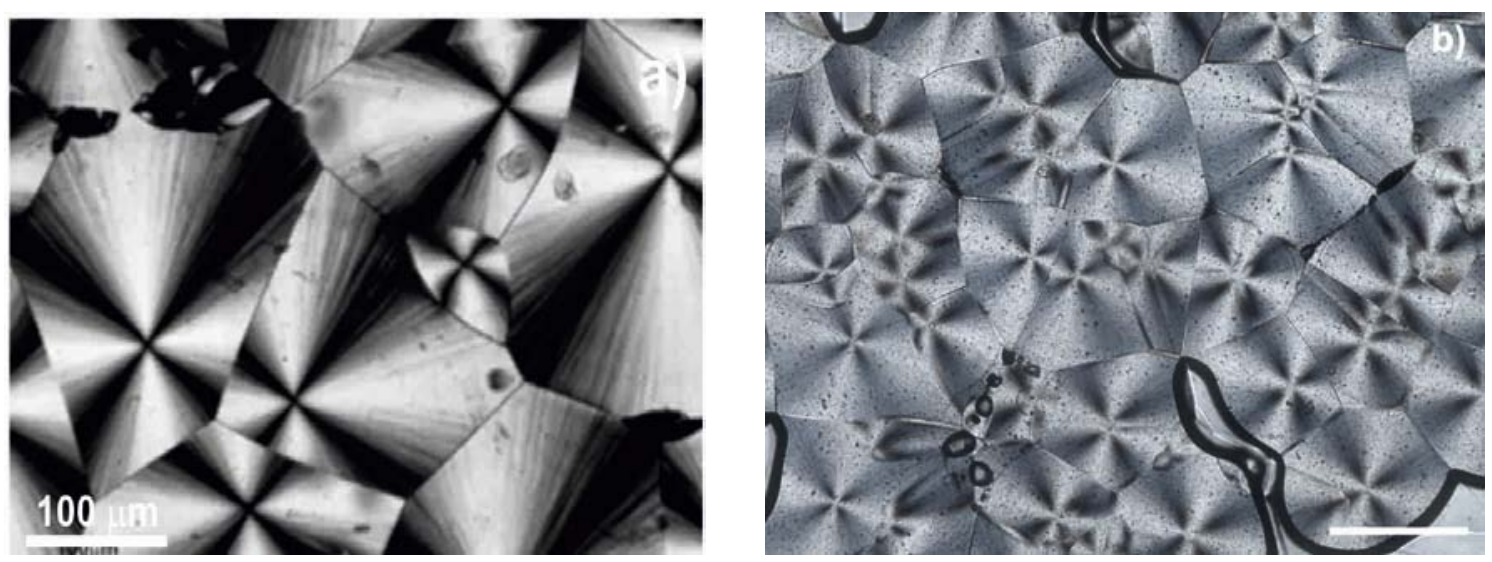

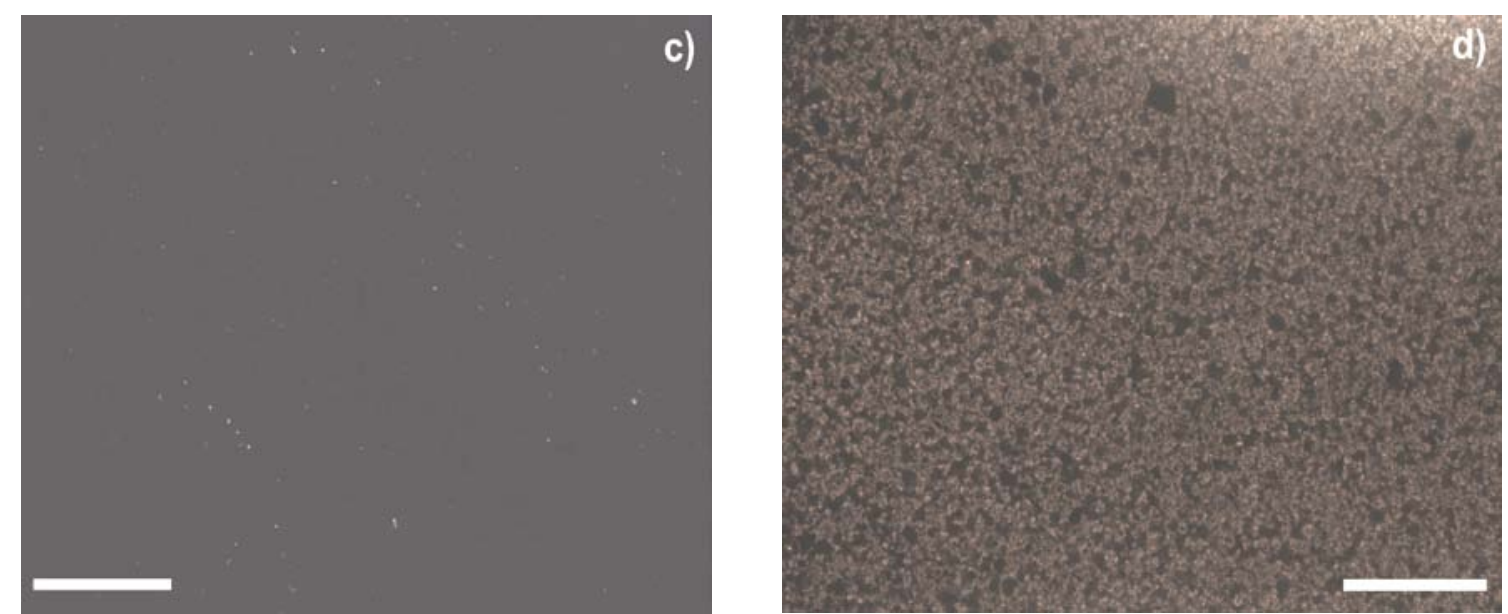

Figure 2 - Spherulitic structure of the samples crystallized at $155^{\circ} \mathrm{C}: a$ ) pure PVDF, $b$ ) $0.1 \%$ of $\left.\mathrm{CoFe}_{2} \mathrm{O}_{4}, c\right) 5 \%$ of $\mathrm{CoFe}_{2} \mathrm{O}_{4}$ and d) $5 \%$ of $\mathrm{NiFe}_{2} \mathrm{O}_{4}$. The scale bar corresponds to $200 \mu \mathrm{m}$ in figures (b) to (d).

\section{c) Crystallization kinetics}

All the crystallization experiments were conducted on a single sample that was not removed from the sample holder of the DSC at any time. In this way, after the first melting, reproducibility is excellent, for instance the uncertainty in the exothermal peak position is smaller than $0.5 \%$ while the uncertainty in the crystalline fraction determined by integration of the peak was smaller than 1\%. Reproducibility in the case of a series of different samples was tested by encapsulating 3 samples of the same nanocomposite composition and subjecting them to melting and subsequent isothermal crystallization. Uncertainty is still smaller than $1 \%$ in peak position and smaller than $2 \%$ in the crystalline fraction. This fact is also an indication of the good dispersion of the nanoparticles in the nanocomposite.

Typical differential scanning calorimetric (DSC) thermograms of pure PVDF and the nanocomposites with different ferrite content are presented in Figure 3. This figure shows the complex effect of the presence of nanoparticles on PVDF crystallization. In the case of the $145{ }^{\circ} \mathrm{C}$ crystallization isotherms of the nanocomposites containing $\mathrm{NiFe}_{2} \mathrm{O}_{4}$ nanoparticles (Figure 3b) the maximum of the exothermic peak shifts towards longer times as nanoparticle content increases. Nevertheless, this behaviour is not the same at higher temperatures, where the peak shifts to longer times for low particles content but then to shorter times for further filler content increase. For instance, at 155 ${ }^{\circ} \mathrm{C}$ the exothermic peak for the sample containing $50 \%$ wt $\mathrm{NiFe}_{2} \mathrm{O}_{4}$ nanoparticles is situated at the same crystallization time than the one observed in pure PVDF (results not 
shown). The crystalline fraction was calculated from the area of the exotherms, assuming a value for the melting enthalpy of the $100 \%$ crystalline $\alpha$-PVDF is 93.07 $\mathrm{J} / \mathrm{g}^{35}$. The crystalline fraction slightly decreases with increasing crystallization temperature. Table 1 collects the values corresponding to 145 and $155{ }^{\circ} \mathrm{C}$. The crystalline PVDF fraction in the sample clearly decreases as the $\mathrm{NiFe}_{2} \mathrm{O}_{4}$ nanoparticles increases. The behavior of the nanocomposites containing $\mathrm{CoFe}_{2} \mathrm{O}_{4}$ particles is quite different: the melting enthalpy with the smallest amount of particles increases with respect to pure PVDF decreasing for further increasing nanoparticle content to reach values slightly below that of pure PVDF for the sample containing $5 \% \mathrm{wt} \mathrm{CoFe}_{2} \mathrm{O}_{4}$. The position of the exothermic crystallization peak of the $0.1 \%$ wt $\mathrm{CoFe}_{2} \mathrm{O}_{4}$ sample at 145 ${ }^{\circ} \mathrm{C}$ shifts towards longer times and then monotonously shifts towards shorter times as the nanoparticles content increases (Figure 3a). As for the $\mathrm{NiFe}_{2} \mathrm{O}_{4}$ nanocomposites, this behaviour varies with increasing crystallization temperatures.

Table I: Evolution of the polymer matrix enthalpy for the PVDF nanocomposites.

\begin{tabular}{|c|c|c|}
\hline Sample & $\begin{array}{c}\Delta \mathbf{H}_{\mathbf{m}} \text { at } \mathbf{1 4 5}^{\circ} \mathbf{C} \\
(\mathbf{J} / \mathbf{g})\end{array}$ & $\begin{array}{c}\Delta \mathbf{H}_{\mathbf{m}} \text { at } \mathbf{1 5 5}^{\circ} \mathbf{C} \\
(\mathbf{J} / \mathbf{g})\end{array}$ \\
\hline $\mathrm{PVDF}$ & 0.58 & 0.52 \\
\hline $0.1 \% \mathrm{CoFe}_{2} \mathrm{O}_{4}$ & 0.67 & 0.57 \\
\hline $0.5 \% \mathrm{CoFe}_{2} \mathrm{O}_{4}$ & 0.56 & 0.49 \\
\hline $5 \% \mathrm{CoFe}_{2} \mathrm{O}_{4}$ & 0.55 & 0.50 \\
\hline $5 \% \mathrm{NiFe}_{2} \mathrm{O}_{4}$ & 0.53 & 0.48 \\
\hline $30 \% \mathrm{NiFe}_{2} \mathrm{O}_{4}$ & 0.48 & 0.34 \\
\hline $50 \% \mathrm{NiFe}_{2} \mathrm{O}_{4}$ & 0.36 & 0.25 \\
\hline
\end{tabular}




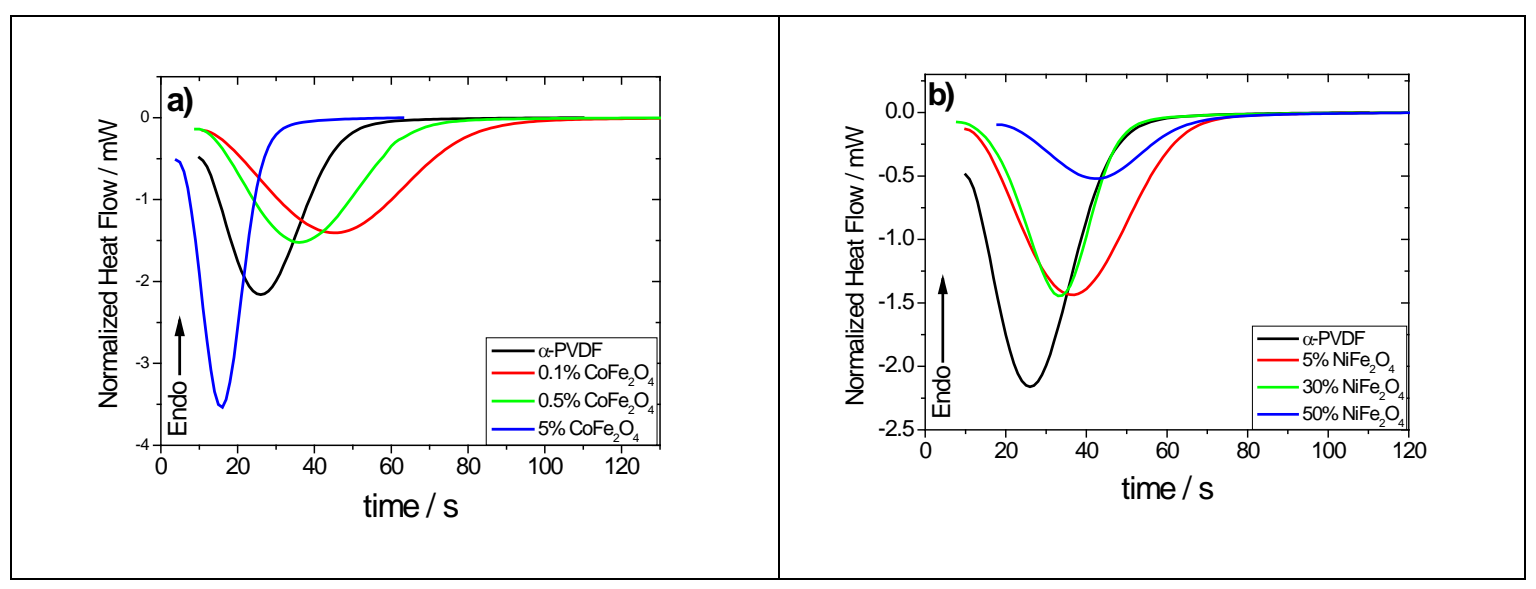

Figure 3: Crystallization thermograms at $145^{\circ} \mathrm{C}$ for $\mathrm{PVDF} /$ ferrite composites with different ferrite concentration: a) $\mathrm{CoFe} 2 \mathrm{O} 4$ and b) $\mathrm{NiFe}_{2} \mathrm{O}_{4}$.

The interpretation of the peak shift in isothermal crystallization is not straightforward. Further, the correlation between the position of the peak and its broadness makes difficult to analyze changes in the shape of the thermogram with nanocomposite composition or temperature. In the case of nanocomposites, mass crystallization kinetics depends on nucleation, interaction between polymer chains and nanoparticles surfaces, possible distortion of spherulite growth due to the presence of particles, co-existence of two crystalline phases with possibly different nucleation and crystal growth rates.

The bell form of the peaks suggests a primary crystallization with no obvious secondary crystallization happening at later stages of isothermal crystallization process. Additionally, it can be observed that the crystallization isotherms show the typical sigmoid shape ${ }^{17}$.

The crystallization kinetics has been frequently analyzed using Avrami model ${ }^{20,21}$. The theoretical background of the model relies on the probability of a given point of the polymer mass to be occupies by growing crystals, considered as spheres whose diameters growth at a given rate and that start growing with a given time dependence. In this way, the theory does not allow accounting for all the subtle details involved in nucleation and growth in a multicomponent system like the nanocomposites and thus it is difficult to correlate the values of the equation parameters with the nanocomposite structure. Nevertheless, it has been shown that it is a very convenient phenomenological equation to describe isothermal crystallization and it will be used in this work to understand the complex nanoparticles content dependence of the crystallization 
thermograms. The relative crystallinity $X_{t}$, as a function of crystallization temperature $T$, can be defined $\mathrm{as}^{20,21}$ :

$$
X_{t}=\frac{\int_{0}^{t}\left(\frac{\partial H}{\partial t}\right) \partial t}{\int_{0}^{\infty}\left(\frac{\partial H}{\partial t}\right) \partial t}
$$

where $\frac{\partial H}{\partial} / \partial t$ is the DSC heat flow. The numerator represents the enthalpy at a given time $t$ and the denominator is the total exothermal enthalpy. The Avrami equation is stated as:

$$
1-X_{t}=\exp \left(-K t^{n}\right)
$$

where $n$ is the Avrami exponent (which in pure polymers has been correlated to the nature of the nucleation and growth geometry of the crystals), and $K$ is a rate constant involving both nucleation and growth rate parameters ${ }^{20,21}$. Equation (3) is applicable only if the nucleation and growth conditions do not change during the crystallization ${ }^{20,21,36}$.

The Avrami exponent can be easily determined if equation (3) is linearized

$$
\ln \left[-\ln \left(1-X_{t}\right)\right]=\ln K+n \ln t
$$

Equation (4) shows that $\mathrm{n}$ is the slope of the plot of $\ln \left[-\ln \left(1-X_{t}\right)\right]$ against $\ln t$. Figure 4 shows this representation for PVDF (Figure 4a) and the nanocomposite containing 50\% $\mathrm{NiFe}_{2} \mathrm{O}_{4}$ (Figure 4b). Interestingly, the temperature dependence of the slope of these curves is quite different in both materials: while in PVDF it increases slightly at low crystallization temperatures and then stabilizes, in the nanocomposite it clearly decreases with temperature after going through a maximum. The values of the Avrami index $n$ are shown in Figure 4 for each temperature. 

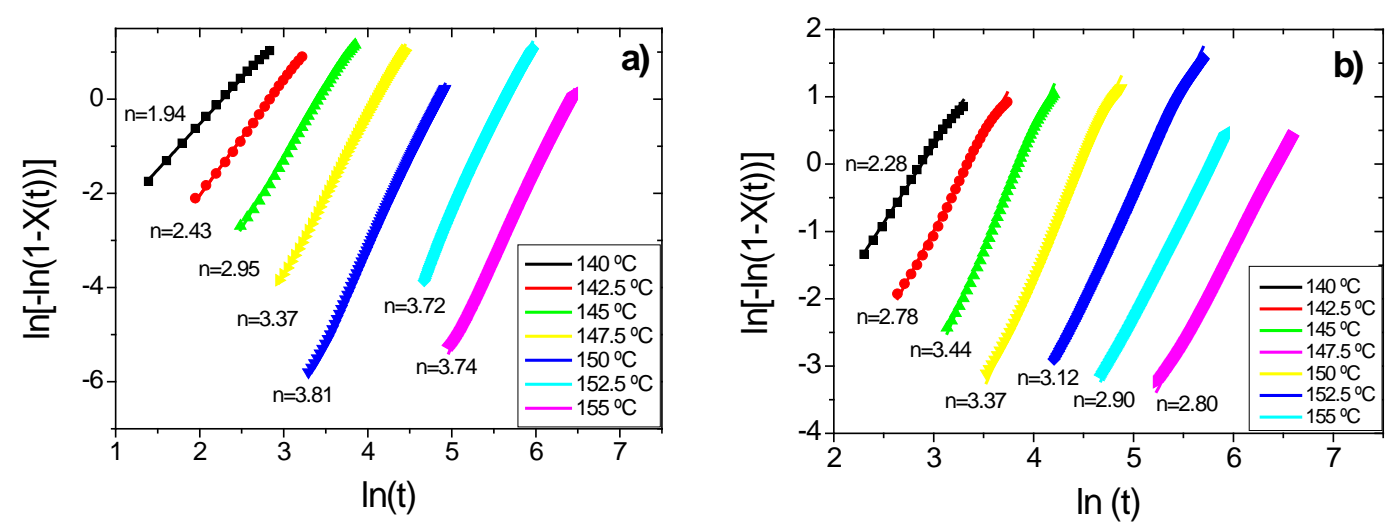

Figure 4 - Plots of $\ln \left[-\ln \left(1-X_{t}\right)\right]$ against Int performed in the a) CoFe2O4 and b) $\mathrm{NiFe}_{2} \mathrm{O}_{4}$ samples crystallized at different temperatures (indicated in the plots) to calculate the Avrami exponent from the fitting with equation (4)

Nevertheless, linearization of equation (3) with the double logarithmic expression of equation (4) gives different statistical weight to the different parts of the thermogram ${ }^{37}$. Non-linear least squares fitting of the measured thermograms were proposed in previous papers to determine both $\mathrm{K}$ and $n$ in equation (3). The heat flow per unit mass, taking into account Eq. 2, can be expressed as:

$$
q(t)=\phi_{c}^{\infty} \frac{\rho_{c}}{\rho} \Delta H_{m} \frac{\partial X_{t}}{\partial t}
$$

where $\rho_{c}$ and $\rho$ are the density of the crystalline phase and the whole sample, respectively, $\phi_{c}^{\infty}$ the maximum volume fraction of the crystalline phase obtained in the isothermal crystallization process and $\Delta H_{m}$ the melting enthalpy ${ }^{17}$.

The substitution of equation (3) into equation (5) gives an equation that can be compared with an experimental thermogram for a pair of parameter values $(K, n)$ and thus $\mathrm{K}$ and $\mathrm{n}$ can be determined using a non-linear least-squares search routine.

The fitting results generated for the isothermal crystallization are shown in figure 5. It can be observed that for the $145{ }^{\circ} \mathrm{C}$ isotherm, the fitting procedure can adjust the experimental data with high accuracy. 

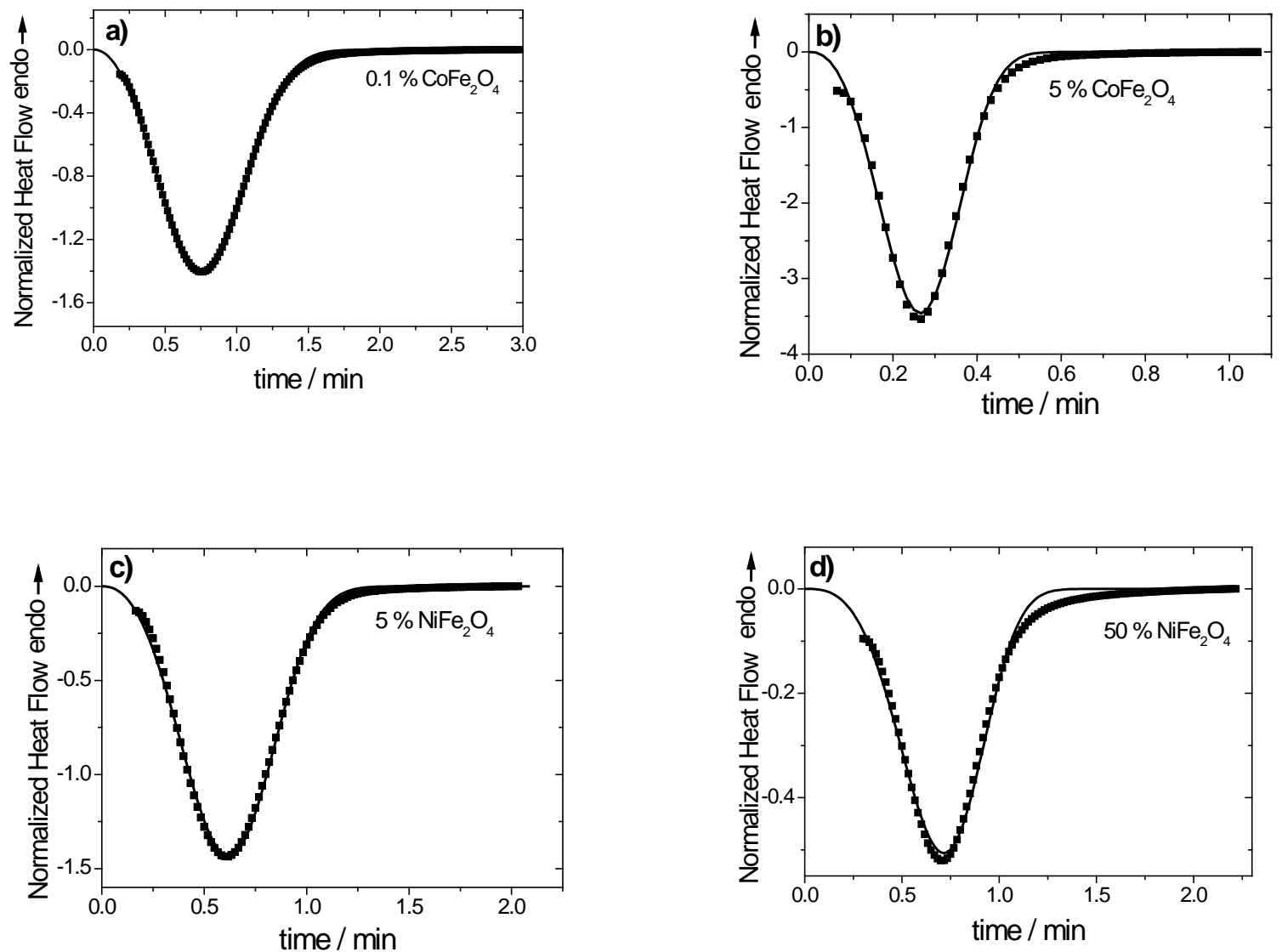

Figure 5 - Avrami fitting results for the PVDF samples with: a) $0.1 \% \mathrm{CoFe}_{2} \mathrm{O}_{4}$, b) $5 \%$ $\mathrm{CoFe}_{2} \mathrm{O}_{4}$, c) $5 \% \mathrm{NiFe}_{2} \mathrm{O}_{4}$ and d) $50 \% \mathrm{NiFe}_{2} \mathrm{O}_{4}$. The dots correspond to the experimental data and the lines to the fitting at $145^{\circ} \mathrm{C}$.

The results of the fitting procedure allow verifying the influence of the nanoparticles in the crystallization behavior of PVDF (Figure 6). Figure 6 confirms that the crystallization kinetics of the pure $\alpha$-PVDF polymer is quite different from the nanocomposite samples. The $n$ parameter for PVDF is quite similar for all experimental temperatures higher than $145^{\circ} \mathrm{C}$ and has a value of approximately 3, already observed by other authors ${ }^{17,36}$. The $n$ value shows that the pure PVDF crystallizes in a spherulitic growth with athermal nucleation, characterized by the fact that all crystallization nuclei are already formed when the crystallization process starts. This fact is confirmed by optical microscopy by the fact that the intersections between most of the spherulites are straight lines (Figure 2). 

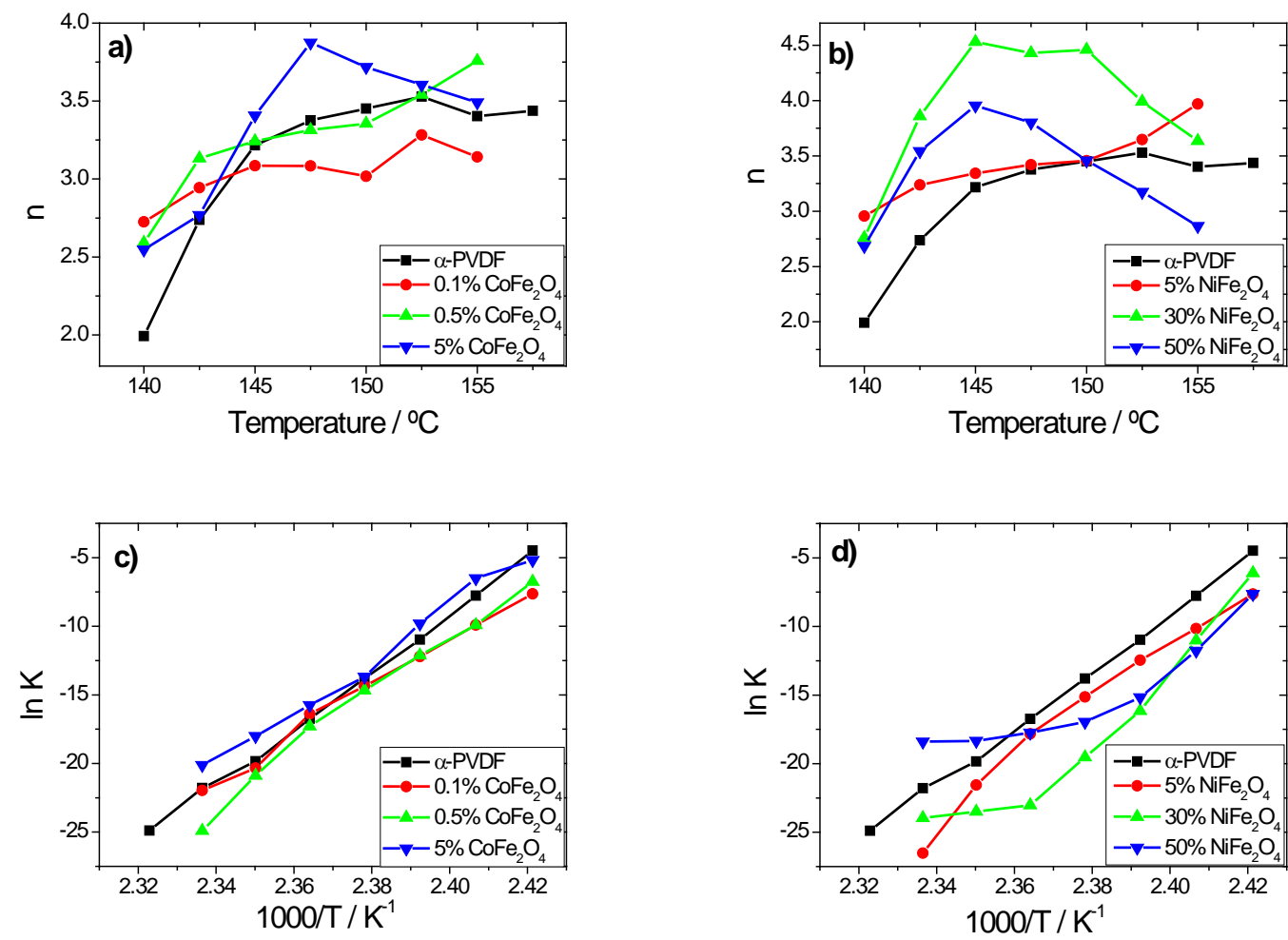

Figure 6 - Evolution of the Avrami parameters with the crystallization temperature for: a) and c) PVDF/CoFe $\mathrm{O}_{4}$ and b) and d) $\mathrm{PVDF} / \mathrm{NiFe}_{2} \mathrm{O}_{4}$, composites.

On the other hand, the temperature dependence of the Avrami exponent of the nanocomposites with low $\beta$-phase content is similar to that of pure $\alpha$-PVDF, while in those in which a high fraction $\beta$-phase is forming (PVDF with $5 \mathrm{wt} \% \mathrm{CoFe}_{2} \mathrm{O}_{4}$ and with 30 and $50 \% w t \mathrm{NiFe}_{2} \mathrm{O}_{4}$ ) the index n after going through a maximum around $147.5{ }^{\circ} \mathrm{C}$, clearly decreases with temperature. Changes in the temperature dependence of the kinetic constant from low to high $\beta$-phase contents in the nanocomposite can also be observed, in particular in Figure 6d, where the phase transformation is observed for larger nanoparticle contents.

Further, the crystallization half-time, $\mathrm{t}_{1 / 2}$, defined as the time at which the extent of crystallization is $50 \%$ completed, can be obtained by equation 6 :

$$
t_{\frac{1}{2}}=\left(\frac{\ln 2}{k}\right)^{\frac{1}{n}}
$$


Reciprocal half-time crystallization $\left(\frac{1}{t_{1 / 2}}\right)$ can be considered approximately proportional to the crystallization growth rate $(G)$.

Figure 7 shows the evolution of the $t_{1 / 2}$ for the pure polymer and for the nanocomposites samples with $\mathrm{CoFe}_{2} \mathrm{O}_{4}$ and $\mathrm{NiFe}_{2} \mathrm{O}_{4}$ both as a function of crystallization temperature and concentration for several temperatures. From the obtained values of $t_{1 / 2}$ it seems that the inclusion of the nanoparticles affect the overall crystallization rate of the nanocomposites when compared to the crystallization rate of the $\alpha$-PVDF. For the $\mathrm{CoFe}_{2} \mathrm{O}_{4}$ nanocomposites with higher amount of nanoparticles $(\mathrm{F}(\beta)=87 \%)$ the crystallization rate is higher than for the pure PVDF, suggesting that the overall crystallization rate of the nanocomposite samples is affected by the crystalline phase of the polymeric matrix. Same result is observed for the samples with $\mathrm{NiF}_{\mathrm{e}} \mathrm{O}_{4}$ nanoparticles.

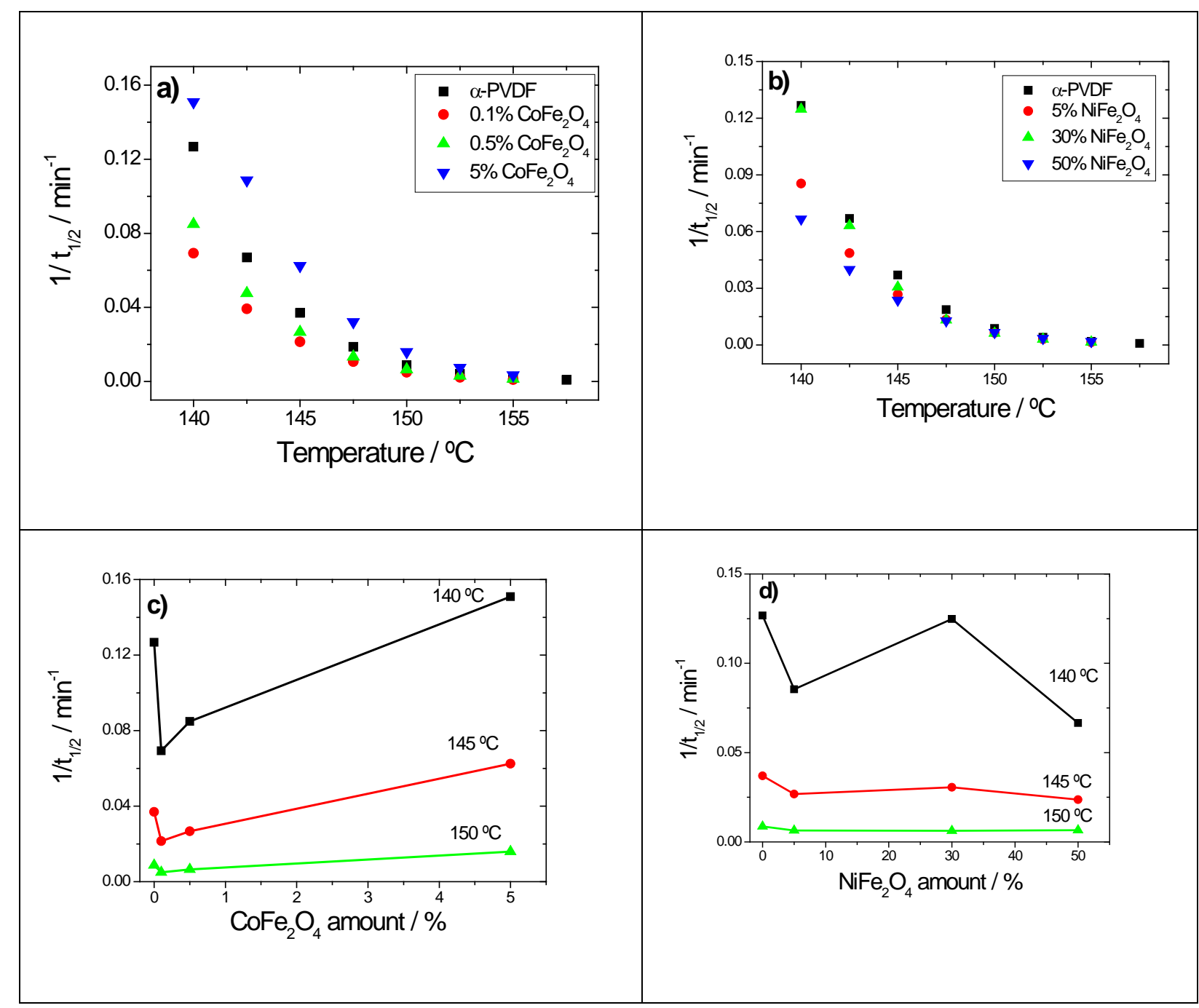


Figure 7 - Reciprocal half-time of the crystallization as a function of the crystallization temperature (above) and nanoparticle concentration for several crystallization temperatures (below) for the: $\mathrm{PVDF} / \mathrm{CoFe}_{2} \mathrm{O}_{4}\left(\mathrm{a}\right.$ and $\mathrm{c}$ ) and PVDF/ $\mathrm{NiFe}_{2} \mathrm{O}_{4}$ (b and d) nanocomposites.

\section{Discussion}

The presence of $\mathrm{CoFe}_{2} \mathrm{O}_{4}$ and $\mathrm{NiFe}_{2} \mathrm{O}_{4}$ nanoparticles induce PVDF crystallization in $\beta$ phase but the fraction of filler nanoparticles needed to produce the same $\beta$ - to $\alpha$-phase ratio in crystallized PVDF is one order of magnitude higher in the case of $\mathrm{NiFe}_{2} \mathrm{O}_{4}$ particles than in $\mathrm{CoFe}_{2} \mathrm{O}_{4}$. This phenomenon was not shown by nanoparticles with other chemical structure such as $\mathrm{Ag}^{34}$ and $\mathrm{Pb}\left(\mathrm{Zr}_{0.53} \mathrm{Ti}_{0.47}\right) \mathrm{O}_{3}{ }^{38}$. Obviously interaction between nanoparticles and PVDF chains induce the all trans conformation in PVDF segments and this structure then propagates in crystal growth. Thus, induction of morphology changes in PVDF crystallization must be some way related to crystal nucleation. In this work, in addition to demonstrate by FTIR the progressive change of crystalline morphology with the presence of a fraction of these nanoparticles, we looked for changes in physical properties related to nucleation kinetics. That nucleation is enhanced by the presence of nanoparticles is clear from the polarized light microscopy that shows an increasing number of spherulites (and thus of crystallization nuclei) as the fraction of nanoparticles increases. It is interesting to observe that as for the ratio of $\beta$ to $\alpha$-phases, to obtain the same effect, i.e., the same increase in spherulite number, a larger fraction of $\mathrm{NiFe}_{2} \mathrm{O}_{4}$ particles than of $\mathrm{CoFe}_{2} \mathrm{O}_{4}$ ones is required (Figures 2c and 2d). This feature still supports the role of nucleation in $\beta$-phase generation. On the other hand nucleation plays an important role in the kinetics of mass crystal growth that was determined by DSC. In principle, for the same crystal growth rate, mass growth rate should increase for increasing nucleation at least in the first period of crystallization when spherulites still do not touch each other. But this is not what the DSC results show. It is clearly observed in the case of $\mathrm{NiFe}_{2} \mathrm{O}_{4}$ particles that in spite of the increase of nucleation shown by light microscopy, mass crystallization rates decrease with nanoparticle contents as shown in Figure 3b. A deeper analysis at the light of the Avrami equation shows that an important change in Avrami's exponent occurs, that at $145^{\circ} \mathrm{C}$ goes from around 3 in PVDF to 4.5 in the nanocomposites with $\mathrm{NiFe}_{2} \mathrm{O}_{4}$ particles, with a simultaneous changes in the kinetic constant K. Trying to correlate these dependence of the macroscopic parameters of the Avrami equation with 
microscopic characteristics of nanoparticle-polymer chain interaction will be few more than speculation because both nucleation kinetics and interaction of the growing crystals with the nanoparticles (note the high number of particles per unit volume in these nanocomposites) can produce changes in kinetic parameters that can have opposite effects of crystal growth rate. Nevertheless, the results show how important is the effect of the presence of nanoparticles. Another interesting point is the important decrease of crystalline fraction of PVDF with increasing $\mathrm{NiFe}_{2} \mathrm{O}_{4}$ nanoparticles content. This means that an important fraction of polymer chains are confined in interphases with the filler particle and are impossible to diffuse to incorporate to the growing crystals. All these phenomena appear in the $\mathrm{CoFe}_{2} \mathrm{O}_{4}$ nanocomposites as well but changes both in $\mathrm{n}$ and in $\mathrm{K}$ are smaller what shows how the large amount of $\mathrm{NiFe}_{2} \mathrm{O}_{4}$ nanoparticles hinders polymer chain reorganizations. It is to notice at this point that the size of the nanoparticles may play an important role in this issue, being the average size of the $\mathrm{NiFe}_{2} \mathrm{O}_{4}$ particles one half on the size of the $\mathrm{CoFe}_{2} \mathrm{O}_{4}$ particles. These facts are in contrast to other fillers such as silica nanoparticles ${ }^{27}$, carbon black ${ }^{31}$ and vapor grown carbon nanofibers that are reported to increase polymer degree of crystallinity ${ }^{33}$.

\section{Conclusions}

In this investigation has been proven that the presence of $\mathrm{Co} \mathrm{Fe}_{2} \mathrm{O}_{4}$ and $\mathrm{NiFe}_{2} \mathrm{O}_{4}$ nanoparticles induce PVDF crystallization in $\beta$-phase but the fraction of filler nanoparticles needed to produce the same $\beta$ - to $\alpha$-phase ratio in crystallized PVDF is one order of magnitude higher in the case of $\mathrm{NiFe}_{2} \mathrm{O}_{4}$ particles than in $\mathrm{Co} \mathrm{Fe}_{2} \mathrm{O}_{4}$. The interaction between nanoparticles and PVDF chains induce the all trans conformation in PVDF segments and this structure then propagates in crystal growth. In this way, magnetoelectric composites taking advantage of the piezoelectric response of $\beta$-PVDF and the magnetostrictive response of the ferrite nanoparticles can be prepared. The nucleation kinetics is enhanced by the presence of nanoparticles, as there are an increasing number of spherulites with increasing nanoparticle content. A deeper analysis at the light of the Avrami equation shows that an important change in the Avrami's exponent occurs with increasing nanoparticle content. Finally, it is observed that an important decrease of crystalline fraction of PVDF with increasing nanoparticles content, indicating that an important fraction of polymer chains are 
confined in interphases with the filler particle and are impossible to diffuse to incorporate to the growing crystals.

\section{Acknowledgements}

This work is funded by FEDER funds through the "Programa Operacional Factores de Competitividade - COMPETE" and by national funds by FCT- Fundação para a Ciência e a Tecnologia, project references NANO/NMed-SD/0156/2007 and PTDC/CTM/69316/2006. V.S. thanks the FCT for the SFRH/BPD/63148/2009 grant. C. R. thanks the INL for a PhD grant. JLGR acknowledge the support of the Spanish Ministry of Education through project No. MAT2010-21611-C03-01 (including the FEDER financial support), project EUI2008-00126, and funding in the Centro de Investigación Principe Felipe in the field of Regenerative Medicine through the collaboration agreement from the Conselleria de Sanidad (Generalitat Valenciana), and the Instituto de Salud Carlos III (Ministry of Science and Innovation).

\section{References}

(1) Priya, L.; Jog, J. P. J. Polym. Sci. Part B: Polym. Phys. 2002, 40, 1682-1689.

(2) Murayama, N.; Nakamura, K.; Obara, H.; Segawa, M. Ultrasonics 1976, 14, 1523.

(3) Sencadas, V.; Gregorio, R.; Lanceros-Méndez, S. J. Macromol. Sci. B Phys. 2009, 48, 514-525

(4) Fukada, E. IEEE Transactions on Ultrasonics, Ferroelectrics and Frequency Control, 2000, 47, 1277-1290.

(5) Lovinger, A. J. Science 1983, 220, 1115-1121.

(6) Sencadas, V.; Gregorio Filho, R.; Lanceros-Mendez, S. J. Non-Cryst. Solid 2006, 352, 2226-2229.

(7) Martins, P.; Nunes, J. S.; Hungerford, G.; Miranda, D.; Ferreira, A.; Sencadas, V.; Lanceros-Méndez, S. Phys. Lett. A 2009, 373, 177-180.

(8) He, L.; Xu, Q.; Hua, C.; Song, R. Polym. Comp. 2010, 31, 921-927. 
(9) Koga, K.; Nakano, N.; Hattori, T.; Ohigashi, H. J. Appl. Phy. 1990, 67, 965-974.

(10) Sadeghi, F.; Ajji, A. Polym. Eng. Sci. 2009, 49, 200-207.

(11) Andrew, J. S.; Clarke, D. R. Langmuir 2008, 24, 8435-8438.

(12) Martins, P.; Costa, C.; Lanceros-Mendez, S. Appl. Phys. A 2011, 103, 233-237.

(13) Hill, N. A. J. Phys. Chem. B 2000, 104, 6694-6709.

(14) G.C. Papaefthymiou; S.R. Ahmed; Kofinas, P. Rev. Adv. Mater. Sci. 2005, 10, 306-313.

(15) Dillon, D. R.; Tenneti, K. K.; Li, C. Y.; Ko, F. K.; Sics, I.; Hsiao, B. S. Polymer 2006, 47, 1678-1688.

(16) Mago, G.; Fisher, F. T.; Kalyon, D. M. J. Nanosci. Nanotech. 2009, 9, 33303340.

(17) Sencadas, V.; Costa, C.; Gómez Ribelles, J.; Lanceros-Mendez, S. J. Mater. Sci. 2010, 45, 1328-1335.

(18) Silva, M. P.; Sencadas, V.; Botelho, G.; Machado, A. V.; Rolo, A. G.; Rocha, J. G.; Lanceros-Mendez, S. Mater. Chem. Phys. 2010, 122, 87-92.

(19) Di Lorenzo, M. L.; Silvestre, C. Prog. Polym. Sci. 1999, 24, 917-950.

(20) Avrami, M. J. Chem. Phys. 1939, 7, 1103-1112.

(21) Avrami, M. J. Chem. Phy. 1941, 9, 177-184.

(22) Ozawa, T. Polymer 1971, 12, 150-158.

(23) Xiu Ling Zhu; Chao Sheng Wang; Biao Wang; Wang, H. P. Iran. Polym. J. 2008, 17, 297-309.

(24) López, L. C.; Wilkes, G. L.; Geibel, J. F. Polymer 1989, 30, 147-155.

(25) Xu, W.; Ge, M.; He, P. J. Polym. Sci. B- Polym. Phys. 2002, 40, 408-414.

(26) Jiasheng, Q.; Pingsheng, H. J. Mater. Sci. 2003, 38, 2299-2304.

(27) Kim, S. H.; Ahn, S. H.; Hirai, T. Polymer 2003, 44, 5625-5634.

(28) Manna, S.; Batabyal, S. K.; Nandi, A. K. J. Phys. Chem. B 2006, 110, 1231812326.

(29) Kim, G. H.; Hong, S. M.; Seo, Y. Phys. Chem. Chem. Phys. 2009, 11, 1050610512.

(30) Chen, X.; Xu, J.; Lu, H.; Yang, Y. J. Polym. Sci. B- Polym. Phys. 2006, 44, 2112-2121.

(31) Zhang, G. Q.; Sun, F.; Gao, L. P.; Wang, L. N.; Shao, M.; Liu, J. Q. J. Compos. Mater. 2007, 41, 1477-1485. 
(32) Raka, L.; Sorrentino, A.; Bogoeva-Gaceva, G. J. Polym. Sci. B- Polym. Phys. 2010, 48, 1927-1938.

(33) Costa, P.; Silva, J.; Sencadas, V.; Costa, C. M.; van Hattum, F. W. J.; Rocha, J. G.; Lanceros-Mendez, S. Carbon 2009, 47, 2590-2599.

(34) Miranda, D.; Sencadas, V.; Sánchez-Iglesias, A.; Pastoriza-Santos, I.; LizMarzán, L. M.; Ribelles, J. L. G.; Lanceros-Mendez, S. J. Nanosci. Nanotech. 2009, 9, 2910-2916.

(35) Nalwa, H. S. Ferroelectric Polymers: Physics, Chemistry and Applications; M. Dekker, Inc.: London, 1995; Vol. 1.

(36) Mancarella, C.; Martuscelli, E. Polymer 1977, 18, 1240-1242.

(37) Strobl, G. R. Physics of polymers: Concepts for understanding their structures and behavior; Springer: Berlin, 1997.

(38) Costa, C. M.; Firmino Mendes, S.; Sencadas, V.; Ferreira, A.; Gregorio Jr, R.; Gómez Ribelles, J. L.; Lanceros-Méndez, S. J. Non-Cryst. Solid 2010, 356, 2127-2133. 

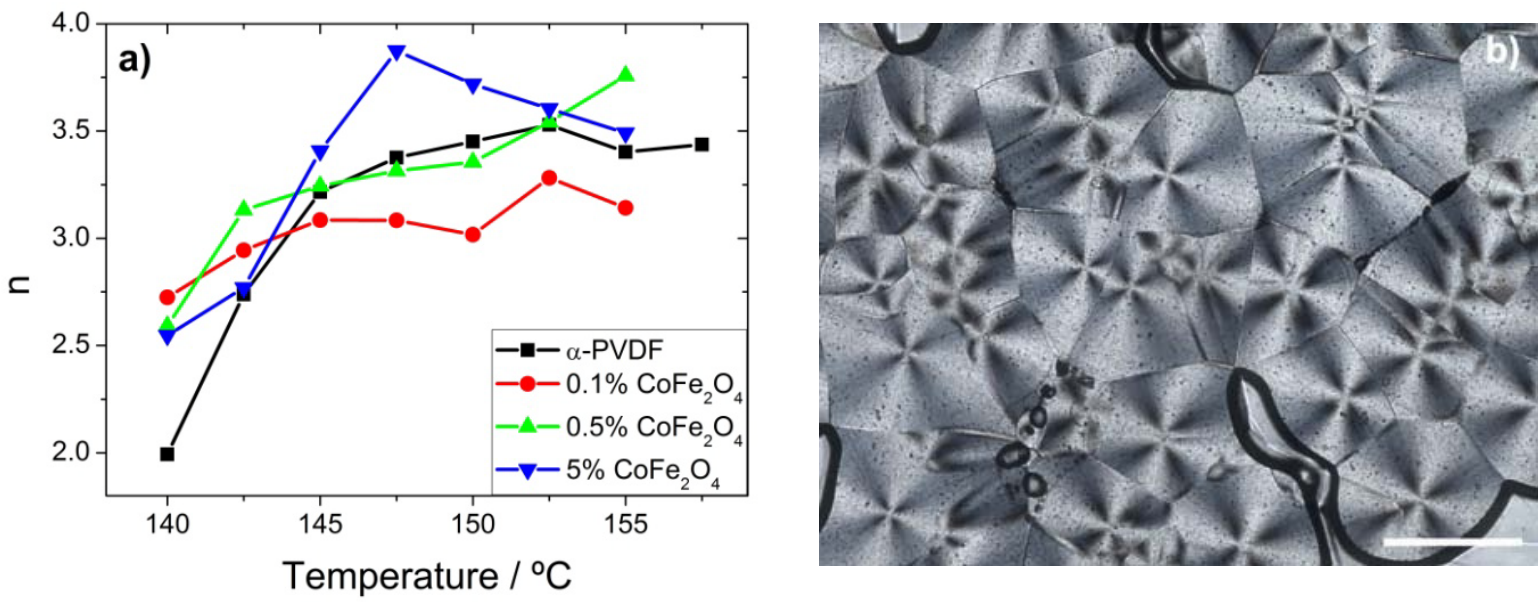